\title{
POSTURA CORPORAL DE OPERADOR NO CARREGAMENTO MECANIZADO DE MADEIRA - ESTUDO DE CASO
}

\author{
Anderson de Costa Paini ${ }^{1}$; Eduardo da Silva Lopes $^{2}$; Felipe Martins de Oliveira ${ }^{3}$ \\ ${ }^{1}$ Discente do Curso de Mestrado em Ciências Florestais da Universidade Estadual \\ do Centro-Oeste - UNICENTRO (paini_engflorestal@hotmail.com) Irati, PR, Brasil \\ ${ }^{2}$ Professor Doutor do Departamento de Engenharia Florestal da UNICENTRO \\ (eslopes@pq.cnpq.br) Irati, PR, Brasil \\ ${ }^{3}$ Discente do Curso de Doutorado em Ciências Florestais da Universidade Estadual \\ do Centro-Oeste - UNICENTRO (eng.felipemartins@live.com) Irati, PR, Brasil
}

Recebido em: 08/04/2016 - Aprovado em: 30/05/2016 - Publicado em: 20/06/2016 DOI: 10.18677/Enciclopedia_Biosfera_2016_083

\begin{abstract}
RESUMO
O objetivo deste estudo foi realizar uma avaliação postural de um operador na atividade de carregamento mecanizado da madeira, visando a melhoria das condições de conforto, segurança e saúde. O estudo foi realizado em uma empresa florestal, no município de Curiúva, Paraná, sendo os dados coletados na atividade de carregamento mecanizado de toras de Pinus taeda para o transporte principal, com uso de uma escavadeira hidráulica. A avaliação postural foi realizada por meio de filmagens, identificando as posturas típicas adotadas pelo operador no trabalho, sendo os dados analisados pelos métodos RULA (Rapid Upper-Limb Assessment) e REBA (Rapid Entire Body Assessment). Os resultados mostraram que a postura adotada pelo operador na posição de neutralidade por longo período de tempo, as mãos e pulsos realizando movimentos repetitivos e as frequentes rotações do tronco apresentam riscos à saúde, necessitando da adoção de medidas ergonômicas para a melhoria nas condições trabalho. Foi ainda verificado a necessidade de alternância de posturas para relaxamento muscular, evitando a ocorrência de fadiga e para a melhoria do conforto e saúde do operador.
\end{abstract}

PALAVRAS-CHAVE: Avaliação postural, colheita mecanizada, ergonomia.

\section{BODY POSTURE OF OPERATOR IN MECHANIZED TIMBER LOADING - CASE STUDY}

\begin{abstract}
The objective of this study was conduct a postural evaluation of one operator in mechanized wood loading, aiming to improve the conditions of comfort, safety and health. The study took place in a forestry company at the city of Curiúva, Paraná, Brazil. Data were collected in mechanized loading of pine logs to main transportation, using a hydraulic excavator. Postural assessment was carried out by shooting an operator, identifying typical postures at work, and data were analyzed by RULA (Rapid Upper-Limb Assessment) and REBA (Rapid Entire Body Assessment) methods. There were identified risk to operator's health due to his posture assumed
\end{abstract}


in the neutral position for a long period of time, the hands and wrists performing repetitive movements and frequent trunk rotations, requiring the adoption of ergonomic measures to improve the work conditions. It was also verified the necessity of changing postures for muscle relaxing, avoiding the occurrence of fatigue and to improve operator's comfort and health.

KEYWORDS: Postural assessment, mechanized harvesting, ergonomics.

\section{INTRODUÇÃO}

O carregamento da madeira é uma atividade muito importante no setor florestal, referindo-se à colocação da madeira no veículo para o transporte até o local de utilização final. Trata-se do elo entre as operações de colheita da madeira e o transporte principal, afetando diretamente o planejamento e a produtividade do sistema logístico (MINETTE et al., 2014).

Apesar do avanço no processo de mecanização ocorrido nas operações florestais, com uso de modernas, confortáveis e produtivas máquinas, ainda existem alguns problemas sob o aspecto ergonômico que necessitam ser solucionados. Dentre tais problemas existentes nas máquinas florestais se destacam as condições ambientais (luminosidade, ruído e vibração), acesso, assentos, comandos e visibilidade nos postos de trabalho (LIMA et al., 2005; FERNANDES et al., 2011), que muitas vezes, foram projetados de forma inadequada, comprometendo as posturas adotas pelos operadores e podendo causar danos à saúde.

Segundo IIDA \& GUIMARÃES (2016), os projetos inadequados de assentos, comandos e postos de trabalho nas máquinas podem forçar o trabalhador a adotar posturas incorretas no trabalho. E quando permanecem por um longo período de tempo em posturas inadequadas, juntamente com movimentos repetitivos, tal situação poderá provocar fortes dores localizadas nos músculos, e consequentemente, o aparecimento de problemas em relação a LER/DORT (Lesões por Esforços Repetitivos/Distúrbios Osteomusculares Relacionados ao Trabalho) (SILVA et al., 2013).

THUN et al. (2011) afirmam que um aspecto importante no projeto de postos de trabalho é a postura corporal que o trabalhador deverá manter durante a execução da atividade. Tal afirmação aparece especificamente no projeto das cabinas de máquinas, de forma que o trabalhador não necessite realizar esforços excessivos. Entretanto, PICOLOTO \& SILVEIRA (2008) relatam que a postura sentada por longo período de tempo ocasiona alteração na coluna lombar, dando origem a uma maior pressão nos discos intervertebrais, resultando em frequentes dores nesta região do corpo.

No caso da colheita da madeira mecanizada é comum os operadores das máquinas realizarem movimentos repetitivos, mantendo posturas assimétricas por períodos prolongados e com ritmo de trabalho acelerado (SILVA et al., 2014). Especificamente no carregamento da madeira, apesar de não haver excesso de esforço físico, é comum os operadores adotarem posturas inadequadas que podem ser originadas, muitas vezes, pelo comprometimento do campo de visão, ocasionado pela posição da grua da máquina ou pela pouca rotação da cabina. Por isso, o operador necessita adotar, muitas vezes, posturas incorretas para visualizar o campo de trabalho (garra e feixe de madeira) durante todo o ciclo do carregamento (SILVA et al., 2014).

Neste sentido, surge a ergonomia que estuda as interações entre o homem e o trabalho, visando a identificação de possíveis problemas e a busca por melhorias 
no bem-estar do ser humano e no desempenho global do sistema (IEA, 2016). Segundo relato de vários autores, a aplicação da ergonomia contribuirá para que o trabalho seja realizado com maior conforto, segurança e saúde, além de contribuir com a melhoria da qualidade e produtividade (BEEVIS \& SLADE, 2005; KLEINER, 2006; GUIMARÃES et al., 2014; GUIMARÃES et al., 2015).

Objetivou-se neste trabalho analisar as posturas típicas adotadas por um operador na atividade de carregamento mecanizado da madeira, visando subsidiar a tomada de decisão para adoção de melhorias nas condições de conforto, satisfação, segurança e saúde.

\section{Área de estudo}

\section{MATERIAL E MÉTODOS}

O estudo foi realizado nas áreas operacionais de colheita da madeira de uma empresa florestal localizada no município de Curiúva, na mesorregião Centro Oriental do estado do Paraná, nas coordenadas geográficas $24^{\circ} 03^{\prime} 02^{\prime \prime} \mathrm{S}$ e $50^{\circ} 31^{\prime}$ 17" W, com altitude média de $776 \mathrm{~m}$. O clima da região, de acordo com a classificação climática de Köppen-Geiger é Cfa, com temperatura média anual de $19^{\circ} \mathrm{C}$, precipitação média anual de $1.455 \mathrm{~mm}$, enquanto o solo predominante foi classificado com textura arenosa e relevo ondulado.

O trabalho foi desenvolvido em plantios de Pinus taeda L., com árvores de volume médio individual com casca de $0,58 \mathrm{~m}^{3}$ e espaçamento $3,0 \mathrm{~m} \times 2,0 \mathrm{~m}$. $\mathrm{O}$ regime de manejo utilizado pela empresa era de corte raso executado aos 17 anos de idade, onde a madeira na forma de toras era destinada ao mercado consumidor.

\section{Caracterização da máquina e operação de carregamento}

O carregador florestal utilizado pelo operador para a execução do trabalho foi uma escavadeira hidráulica (Figura 1), com potência nominal do motor de $70 \mathrm{~kW}$, peso operacional de $13,6 \mathrm{t}$, material rodante de esteiras e equipado com garra com área de abertura de $0,80 \mathrm{~m}^{2}$. O posto de trabalho possui diversas regulagens de altura do assento, inclinação do encosto e distância dos joysticks.

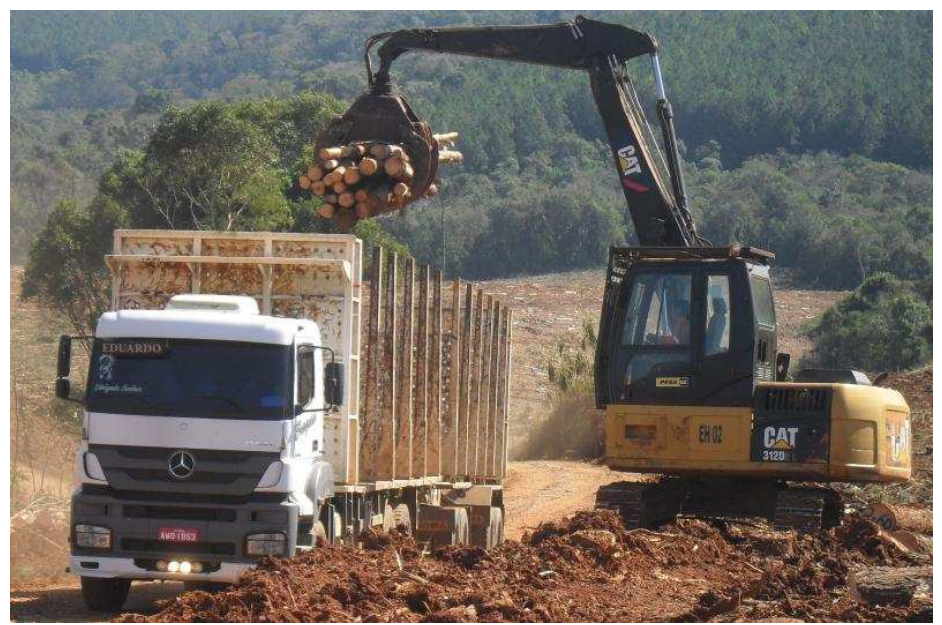

FIGURA 1 - Carregador florestal utilizado pelo operador.

O sortimento da madeira carregada no veículo de transporte principal durante a coleta de dados apresentava comprimento de toras de 3,60 m e diâmetros de 8 e $25 \mathrm{~cm}$ na extremidade de menor e maior diâmetro, respectivamente. O ciclo 
operacional do carregamento foi subdividido nos seguintes elementos parciais: Carregamento da Garra (CG): tempo consumido pela movimentação da garra vazia do veículo até a pilha de madeira e carregamento do feixe de toras; e Descarregamento da Garra (DG): tempo consumido pelo deslocamento da garra com o feixe de toras da pilha de madeira até o compartimento de carga do veículo de transporte, incluindo os movimentos necessários para acomodação da carga.

\section{Operador estudado}

A avaliação postural foi realizada em um operador do sexo masculino com idade de 39 anos, estatura de 1,67 m, massa corporal de $102,5 \mathrm{Kg}$ e experiência de 13 anos na atividade de carregamento mecanizado. O operador foi definido em acordo com a empresa, sendo considerado um indivíduo de perfil característico que atuava na operação de carregamento florestal, apresentando produtividade média em relação à meta estabelecida pela empresa. O operador estudado teve participação voluntária, recebendo esclarecimentos quanto aos objetivos e uso das imagens da pesquisa, por meio da assinatura do Termo de Consentimento Livre e Esclarecido (TCLE), em atendimento à Resolução n. 466/2012 do Conselho Nacional de Saúde do Ministério da Saúde (BRASIL, 2013).

\section{Coleta de dados}

Inicialmente foram realizadas filmagens do operador na execução da operação de carregamento, por meio da instalação de duas câmeras tipo DVR com unidade gravadora de quatro canais e cartões de memória no interior da cabina da máquina. Uma câmera foi orientada para o interior, de modo a captar as posturas típicas adotadas pelo operador no trabalho e outra para o exterior, com a finalidade de captar a operação propriamente dita e identificação do tempo de trabalho, relacionando posteriormente com as posturas adotadas pelo operador (Figura 2).
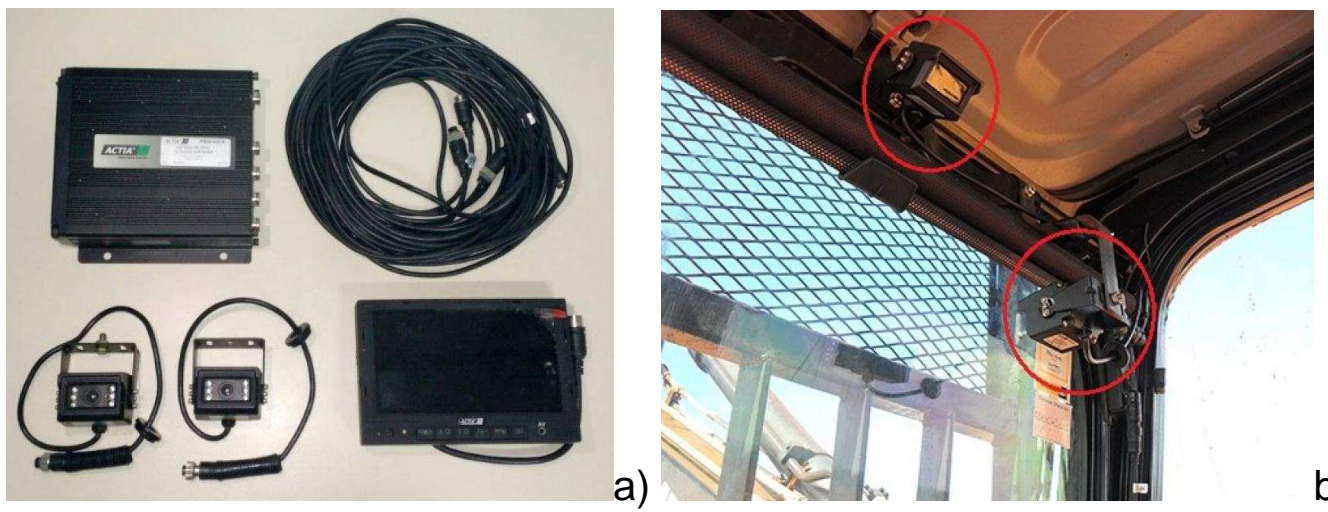

a)

b)

FIGURA 2 - Conjunto da câmera utilizada no estudo (a); Local de instalação das câmeras no interior da cabina do carregador florestal (b).

Como houve variações das posturas adotadas pelo operador e por se tratar de uma operação cíclica com repetição das posturas durante a jornada de trabalho, foram identificadas as posturas típicas adotas pelo operador dentro de cada elemento parcial do ciclo operacional. Posteriormente, as filmagens obtidas foram levadas para o laboratório, sendo analisadas por meio do software MSShow $\AA$. Foram selecionados 10 ciclos operacionais do carregamento da madeira para identificação e "congelamento" das imagens nas posturas típicas para posterior análise biomecânica. 


\section{Análise Postural}

As análises das posturas típicas adotadas pelo operador no carregamento foram realizadas por meio dos métodos RULA - Rapid Upper-Limb Assessment e REBA - Rapid Entire Body Assessment.

O método RULA, desenvolvido por McATAMNEY \& CORLETT (1993) possui foco na avaliação da sobrecarga dos membros superiores. Avalia o trabalho muscular de forma estática, as forças aplicadas nos segmentos do corpo humano, e por meio de diagramas é realizado o reconhecimento das angulações dos movimentos nos diferentes membros do corpo, sendo apresentados em dois grupos (A e B) além de incluir análise de repetitividade e manuseio de cargas (Figuras 1 e 2).

\begin{tabular}{|c|c|c|c|c|c|c|}
\hline Escores & 1 & 2 & 2 & 3 & 4 & Ajustes \\
\hline \multirow{3}{*}{ Braços } & & & & & & + 1 ombro elevado \\
\hline & & & & & & + 1 braço abduzido \\
\hline & $\begin{array}{c}20^{\circ} \text { de extensão a } \\
20^{\circ} \text { de flexão }\end{array}$ & $\begin{array}{l}>20^{\circ} \text { de } \\
\text { extenção }\end{array}$ & $\begin{array}{l}20 \text { a } 45^{\circ} \text { de } \\
\text { flexão }\end{array}$ & $\begin{array}{c}>45 \text { a } 90^{\circ} \text { de } \\
\text { flexão }\end{array}$ & $\begin{array}{l}\geq 90^{\circ} \text { de } \\
\text { flexão }\end{array}$ & - 1 braço apoiado \\
\hline \multirow[t]{2}{*}{ Antebraços } & & & & & & $\begin{array}{c}\text { + } 1 \text { Antebraço cruza } \\
\text { o plano sagital }\end{array}$ \\
\hline & 60 a $100^{\circ}$ de flexão & $<60^{\circ}$ de fle & $\begin{array}{l}\text { ou }>100^{\circ} \mathrm{de} \\
0\end{array}$ & & & $\begin{array}{c}\text { +1 Antebraço } \\
\text { rotacionado externo } \\
\text { ao tronco }\end{array}$ \\
\hline \multirow[t]{2}{*}{ Punhos } & & & & & & \\
\hline & $\begin{array}{c}0^{\circ} \text { Neutro ou meia } \\
\text { inclinação de } \\
\text { pronação ou } \\
\text { supinação }\end{array}$ & $\begin{array}{l}15^{\circ} \text { de flexã } \\
\text { ou total pro }\end{array}$ & $\begin{array}{l}5^{\circ} \text { de extensão } \\
\text { o o supinação }\end{array}$ & $\begin{array}{c}\geq 15^{\circ} \text { de flexão } \\
\text { ou extensão }\end{array}$ & & $\begin{array}{c}+1 \text { Desvio ulnar } \\
\text { ou radial }\end{array}$ \\
\hline
\end{tabular}

FIGURA 1 Escores dos segmentos corpóreos do grupo A no método RULA.

Fonte: Adaptado de MCATAMNEY \& CORLETT (1993). 


\begin{tabular}{|c|c|c|c|c|c|}
\hline Escores & 1 & 2 & 3 & 4 & Ajustes \\
\hline Pescoço & $0^{\circ}$ a $10^{\circ}$ de flexão & 10 a $20^{\circ}$ de flexão & $>20^{\circ}$ de flexão & Em extensão & $\begin{array}{l}+1 \text { pescoço } \\
\text { torcido ou } \\
\text { rotacionado } \\
+1 \text { pescoço } \\
\text { inclinado } \\
\text { lateralmente }\end{array}$ \\
\hline Tronco & $\begin{array}{l}0^{\circ} \text { ou bem apoiado } \\
\text { quando sentado }\end{array}$ & 0 a $20^{\circ}$ de flexão & 0 a $20^{\circ}$ de flexão & $>60^{\circ}$ de flexão & $\begin{array}{c}+1 \text { tronco } \\
\text { torcido ou } \\
\text { rotacionado } \\
\\
+1 \text { tronco } \\
\text { inclinado } \\
\text { lateralmente }\end{array}$ \\
\hline Pernas & $\begin{array}{c}\text { Pernas e pés bem } \\
\text { apoiadose } \\
\text { equilibrados }\end{array}$ & $\begin{array}{c}\text { Pernas e pés não } \\
\text { estão corretamente } \\
\text { apoiados e } \\
\text { equilibrados }\end{array}$ & & & \\
\hline
\end{tabular}

FIGURA 2 Escores dos segmentos corpóreos do grupo B no método RULA. Fonte: Adaptado de McATAMNEY \& CORLETT (1993).

Cada fator avaliado recebeu uma pontuação, cujos resultados obtidos dos grupos $\mathrm{A}$ e $\mathrm{B}$ foram cruzados, adicionando à análise, pontuações referentes ao uso da musculatura, ou seja, se a postura era estática e mantida por um período superior a um minuto ou movimentos repetitivos com ocorrência superior a quatro minutos, além de incluir a carga de trabalho.

Desta forma, o escore final obtido para cada postura típica adotada pelo operador foi comparada com os níveis de ação definidos pelo método:

- Nível 1: Pontuação 1 ou 2 - postura aceitável, se não for mantida ou repetida por longos períodos;

- Nível 2: Pontuação 3 ou 4 - são necessárias mais investigações e possível necessidade de mudanças;

- Nível 3: Pontuação 5 ou 6 - necessárias investigações e mudanças a curto prazo; e

- Nível 4: Pontuação igual ou maior que 7 - necessárias investigações e mudanças imediatas.

O REBA, desenvolvido por HIGNETT \& McATAMNEY (2000) é um método de avaliação postural semiquantitativo derivado dos métodos RULA, OWAS e NIOSH. Avalia a atividade muscular estática adotada pelo corpo humano, as angulações dos movimentos, as cargas manuseadas, a repetitividade no trabalho e a qualidade da pega executada pelo trabalhador. No método, o corpo humano é segmentado em dois grupos de membros, $\mathrm{A}$ e $\mathrm{B}$, conforme demonstrados nas Figuras 3 e 4. 


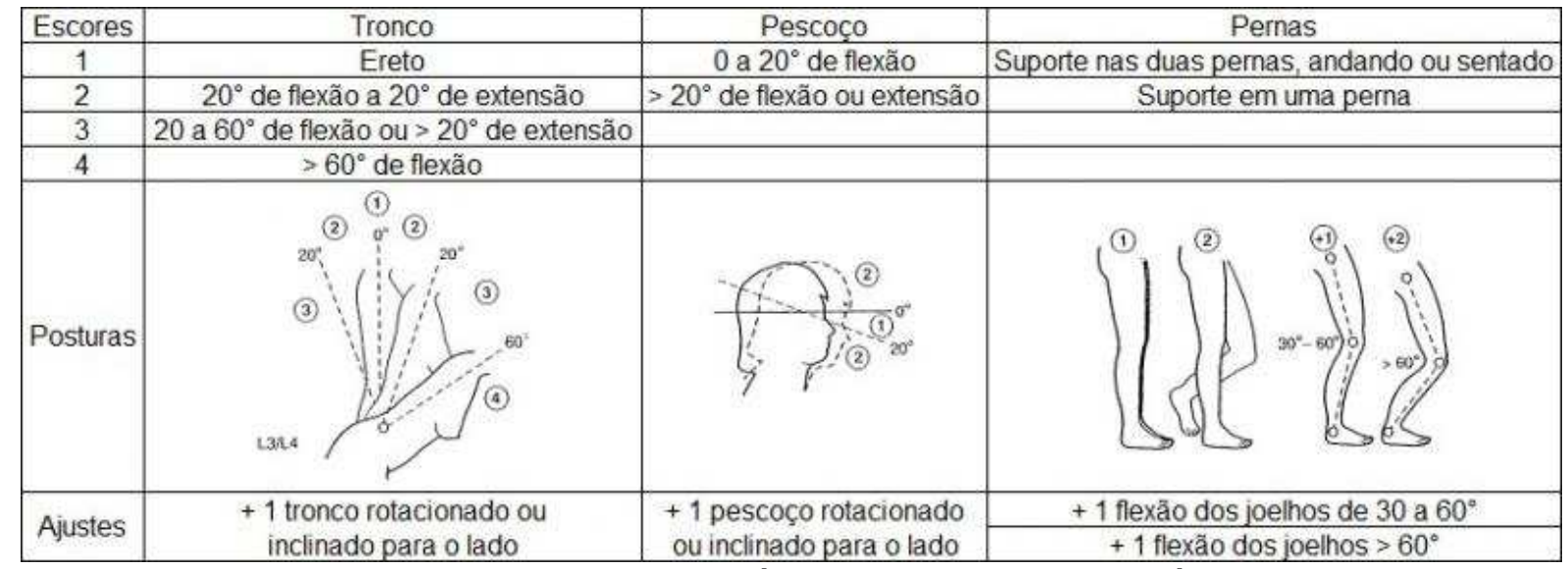

FIGURA 3 Escores dos segmentos corpóreos do grupo A no método REBA. Fonte: Adaptado de HIGNETT \& McATAMNEY (2000).

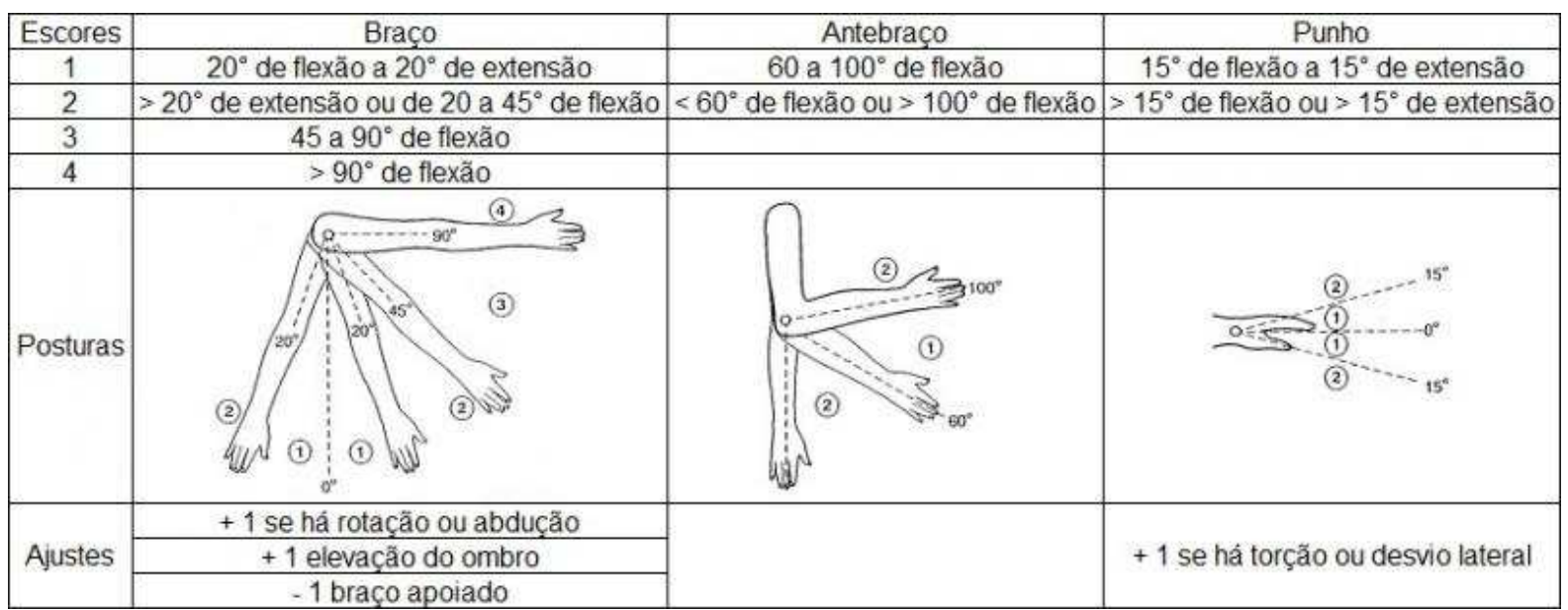

FIGURA 4 Escores dos segmentos corpóreos do grupo B.

Fonte: Adaptado de HIGNETT \& McATAMNEY, (2000).

O método REBA avaliou os membros corpóreos e indicou uma pontuação, onde os resultados foram advindos do cruzamento entre os grupos $A$ e $B$, juntamente com as pontuações referentes à qualidade da pega, as posturas com uma ou mais partes do corpo humano mantidas por mais de um minuto, movimentos repetitivos acima de quatro vezes por minuto ou grandes mudanças posturais.

Após a obtenção do escore final referente às posturas típicas, foram encontrados os níveis de ação definidos pelo método.

- Nível 0: Pontuação 1 - risco inexistente, postura aceitável, não havendo necessidade de providências;

- Nível 1: Pontuação 2 ou 3 - risco baixo, podendo haver necessidade de providências;

- Nível 2: Pontuação 4 a 7 - risco médio, havendo necessidade de providências;

- Nível 3: Pontuação entre 8 e 10 - risco alto, havendo necessidade de providências a curto prazo; e

- Nível 4: Pontuação entre 11 e 15 - risco muito alto, havendo necessidade de providências imediatamente. 


\section{RESULTADOS E DISCUSSÃO}

Os resultados das avaliações posturais do operador na execução do carregador de madeira pelos métodos RULA e REBA são apresentada na Figura 5. Foram identificadas duas posturas típicas em cada elemento do ciclo operacional do carregamento da madeira.

\begin{tabular}{|c|c|c|c|c|c|}
\hline \multirow{2}{*}{\multicolumn{2}{|c|}{ Postura Típica }} & \multicolumn{4}{|c|}{ Método } \\
\hline & & \multicolumn{2}{|c|}{ RULA } & \multicolumn{2}{|c|}{ REBA } \\
\hline Cód. & Imagem & Resultado & Diagnóstico & Resultado & \begin{tabular}{|l|l} 
Diagnstico \\
\end{tabular} \\
\hline CG1 & & $\begin{array}{l}\text { Pontuação: } 3 \\
\text { Nível Ação: } 2\end{array}$ & $\begin{array}{c}\text { Necessárias } \\
\text { mais } \\
\text { investigações } \\
\text { com possível } \\
\text { necessidade } \\
\text { de } \\
\text { mudanças. }\end{array}$ & $\begin{array}{l}\text { Pontuação: } 4 \\
\text { Nível Ação: } 2 \\
\text { Risco: médio }\end{array}$ & $\begin{array}{l}\text { Necessárias } \\
\text { providências. }\end{array}$ \\
\hline CG2 & & $\begin{array}{l}\text { Pontuação: } 5 \\
\text { Nível Ação: } 3\end{array}$ & $\begin{array}{c}\text { Necessárias } \\
\text { investigações } \\
\text { com } \\
\text { mudanças } \\
\text { em breve. }\end{array}$ & $\begin{array}{l}\text { Pontuação: } 6 \\
\text { Nível Ação: } 2 \\
\text { Risco: médio }\end{array}$ & $\begin{array}{l}\text { Necessárias } \\
\text { providências. }\end{array}$ \\
\hline DG1 & & $\begin{array}{l}\text { Pontuação: } 3 \\
\text { Nível ação: } 2\end{array}$ & $\begin{array}{c}\text { Necessárias } \\
\text { mais } \\
\text { investigações } \\
\text { com possível } \\
\text { necessidade } \\
\text { de } \\
\text { mudanças. }\end{array}$ & $\begin{array}{l}\text { Pontuação: } 4 \\
\text { Nível Ação: } 2 \\
\text { Risco: médio }\end{array}$ & $\begin{array}{l}\text { Necessárias } \\
\text { providências. }\end{array}$ \\
\hline DG2 & & $\begin{array}{l}\text { Pontuação: } 5 \\
\text { Nível ação: } 3\end{array}$ & $\begin{array}{c}\text { Necessárias } \\
\text { investigações } \\
\text { com } \\
\text { mudanças } \\
\text { em breve. }\end{array}$ & $\begin{array}{l}\text { Pontuação: } 6 \\
\text { Nível Ação: } 2 \\
\text { Risco: médio }\end{array}$ & $\begin{array}{l}\text { Necessárias } \\
\text { providências. }\end{array}$ \\
\hline
\end{tabular}

FIGURA 5 Avaliação postural do operador durante o ciclo operacional de carregamento da madeira.

CG: carregamento da garra; DG: descarregamento da garra.

Como pode ser observado, apesar de apresentarem diferenças visuais, principalmente nas inclinações do tronco e da cabeça, todas as posturas típicas adotadas pelo operador durante o trabalho foram classificadas com riscos por ambos os métodos de avaliação postural. O método RULA apontou a existência de carga nos membros superiores e a necessidade de maiores investigações com possível necessidade de mudanças nas posturas CG1 e DG1, enquanto que para as posturas CG2 e DG2, houve a necessidade de investigações com mudanças em breve, explicado principalmente pela postura inadequada adotada pelo operador com a inclinação do tronco e do pescoço. Já no método REBA, que considerou as 
posturas de todo o corpo, houve indícios de risco médio em todas as posturas adotadas, com necessárias providências ou correções.

Apesar das posturas CG1 e DG1 mostrarem o operador sentado, com a coluna vertebral na posição próxima da neutralidade, ambas apresentaram valores significativos com relação à permanência nesta mesma postura por longo período de tempo, além de alta repetitividade nos movimentos das mãos, acima de quatro vezes por minuto. Tal situação é comum nesta atividade, porém podendo comprometer a articulação entre as mãos e os antebraços pela rotação constante do corpo, podendo consequentemente, causar riscos de lesão por movimentos repetitivos.

As posturas CG2 e DG2 apresentaram em grande parte, as mesmas características das posturas CG1 e DG1, com riscos à saúde do operador. Entretanto, tais posturas mostraram ainda uma inclinação de 20 a 60 graus no pescoço e tronco do operador. Tal postura inadequada ocorreu pela obstrução do campo de visão, ocasionada pela grua da máquina e pelo procedimento incorreto adotado no trabalho, não ocorrendo o giro total da cabine da máquina durante a realização do carregamento. Com isso, o operador normalmente mantém-se curvado para os lados por alguns momentos para visualização da tarefa com precisão.

DUL \& WEERDMEESTER (2012) afirmam que, na posição sentada, quando o tronco e a cabeça se mantêm inclinados, o pescoço e as costas normalmente ficam submetidos às tensões que podem causar dores, bem como pode comprometer 0 dorso devido à necessidade de girar o corpo com o assento fixo. É importante ressaltar que ambos os métodos de avaliação apontaram problemas nas posturas adotadas pelo operador, com riscos ergonômicos e necessitando de maiores investigações e providências do ponto de vista ergonômico para a melhoria das condições de conforto e saúde do operador.

DOMINGO et al. (2015) utilizando os métodos RULA e REBA, constataram diversas posturas lesivas nos trabalhadores da construção civil nas Filipinas, enquanto YOON et al. (2016) utilizaram o método REBA na identificação da rotação do corpo de trabalhadores na linha de montagem de veículos automotores, classificando os postos de trabalho com alta ou baixa exigência física, propondo um modelo de rotação de tarefas com base no uso sucessivo da mesma região corporal.

Os tempos médios de permanência do operador em cada postura típica durante o ciclo de carregamento da madeira é ilustrado na Figura 6. Como pode ser visto, a postura típica que ocupou a maior percentagem do tempo do ciclo de trabalho foi a DG 1 com $39 \%$ do tempo total.

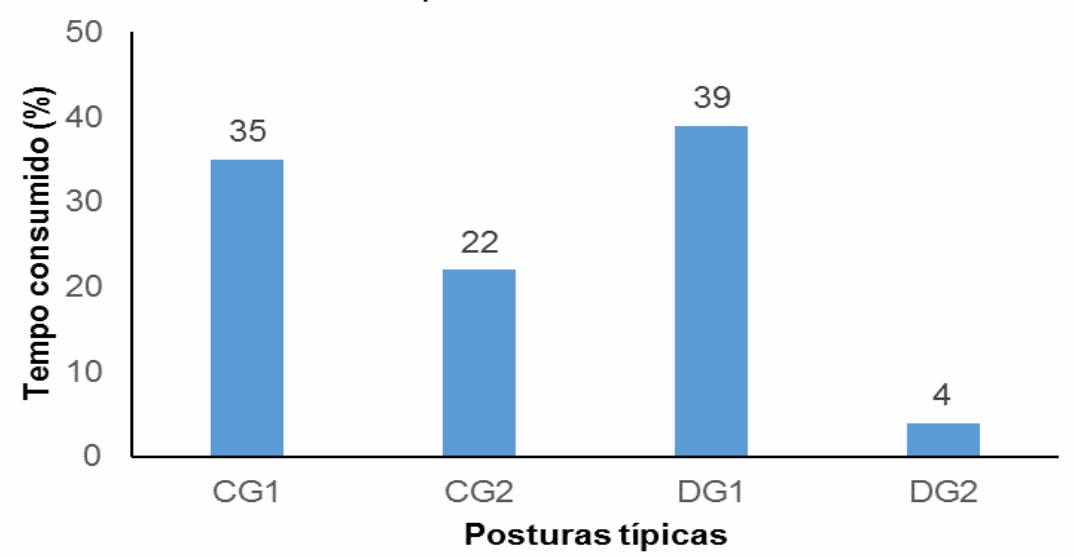

FIGURA 6 - Tempos percentuais médios de permanência do operador em cada postura típica no carregamento da madeira. 
Entretanto, considerando o elemento parcial como um todo (carregamento ou descarregamento da garra), pode-se dizer que o carregamento da garra consumiu 0 maior tempo, com $57 \%$ do ciclo operacional efetivo, contra $43 \%$ de descarregamento da grua. Além disso, pode-se afirmar que o trabalhador permaneceu $26 \%$ do tempo sentado com a coluna e o pescoço inclinado (posturas CG2 e DG2), caracterizandose como prejudicial à saúde do trabalhador devido aos esforços localizados principalmente na região da coluna lombar e cervical.

Apesar das avaliações posturais ter demonstrado os mesmos níveis de riscos e medidas de ação em todas as posturas adotadas pelo operador, é importante relacionar o longo tempo de permanência do operador nestas posturas incorretas. Tal fato poderá causar desconforto do operador no trabalho, e podendo no futuro, afetar a segurança e saúde, considerando tratar-se de um trabalho cíclico e de alta repetitividade.

Neste sentido, DUL \& WEERDMEESTER (2012) relatam que as posturas prolongadas na mesma posição poderão prejudicar os músculos e as articulações, causando tensões localizadas com maior exigência física. GERASIMOV \& SOKOLOV (2014) também relatam que os operadores de máquinas florestais podem ser afetados por injúrias no pescoço, braços e coluna cervical, sendo que as principais causas são os excessivos períodos de tempo na posição sentada e estático, com a adoção de posturas ergonomicamente impróprias.

Por fim, mesmo que os operadores de máquinas florestais estejam expostos a menores desgastes físicos devido à mecanização das atividades, COUTO (2002) afirma que há maior exigência física quando o trabalhador permanece por longos períodos de tempo executando o trabalho com a adoção de posturas estáticas. Portanto, fica evidente a necessidade de adoção de medidas ergonômicas, como as pausas de recuperação, visando equalizar a biomecânica do organismo e balanceando a sobrecarga do trabalho.

\section{CONCLUSÕES}

Com base na análise e discussão dos resultados, conclui-se que:

- Todas as posturas típicas adotadas pelo operador do carregador florestal apresentaram risco ergonômico, podendo causar no futuro danos à saúde e afetar a produtividade.

- A repetitividade de movimentos das mãos e punhos e a permanência por longo período de tempo na posição estática foram as principais causas dos riscos posturais no operador na execução do carregamento da madeira.

- Como medida ergonômica pode ser adotada a alternância das posturas, com introdução de pausas de recuperação e ginástica laboral distribuídos durante a jornada de trabalho.

\section{AGRADECIMENTOS}

À Capes pela concessão da bolsa de estudo ao primeiro autor, ao operador participante e à empresa florestal pelo apoio e disponibilização da área de estudo. 


\section{REFERÊNCIAS}

BEEVIS, D.; SLADE, I. M. Ergonomics - costs and benefits. Applied Ergonomics, v. 34 n. 5, p. 413-418, 2005. Disponível em: <http://dx.doi.org/10.1016/S00036870(03)00061-9>. doi:10.1016/S0003-6870(03)00061-9

BRASIL. Conselho Nacional de Saúde. Resolução № 46 6, de 12 de dezembro de 2012. Aprova normas regulamentadoras de pesquisas envolvendo seres humanos. Brasília: Diário Oficial da União, 13 jun. 2013. Seção I p. 59.

COUTO, H. A. Ergonomia aplicada ao trabalho em 18 lições. Belo Horizonte: Ergo, 2002. 201 p.

DOMINGO, J. R. T.; PANO, M. T. S.; ECAT, D. A. G.; SANCHEZ, N. A. D. G.; CUSTODIO, B. P. Risk Assessment on Filipino Construction Workers. Procedia Manufacturing, v. 2, p. 1854-1860, 2015. Disponível em: <http://dx.doi.org/10.1016/j.promfg.2015.07.226>. doi:10.1016/j.promfg.2015.07.226

DUL, J. WEERDMEESTER, B. Ergonomia prática. Trad. Itiro lida. 3. ed. São Paulo: Blucher, 2012. $163 \mathrm{p}$.

FERNANDES, H. C.; BRITO, A. B.; MINETTE, L. J.; LEITE, D. M.; LEITE, E. S. Aplicação de índices ergonômicos na avaliação da cabine de um trator florestal "Feller-Buncher", Scientia Forestalis, v. 39, n. 90, p. 273-281, 2011.

GERASIMOV, Y.; SOKOLOV, A. Ergonomic evaluation and comparison of wood harvesting systems in Northwest Russia. Applied ergonomics, v. 45, n. 2, p. 318338, 2014. Disponível em: <http://dx.doi.org/10.1016/j.apergo.2013.04.018>. doi:10.1016/j.apergo.2013.04.018

GUIMARÃES, L. B. M.; ANZANELLO, M. J.; RIBEIRO, J. L. D.; SAURIN, T. A. Participatory ergonomics intervention for improving human and production outcomes of a Brazilian furniture company. International Journal of Industrial Ergonomics, v. 49, p. 97-107, set. 2015. Disponível em: <http://dx.doi.org/10.1016/j.ergon.2015.02.002>. doi:10.1016/j.ergon.2015.02.002

GUIMARÃES, L. B. M.; RIBEIRO, J. L. D.; RENNER, J. S.; OLIVEIRA, P. A. B. Worker evaluation of a macroergonomic intervention in a Brazilian footwear company. Applied Ergonomics, v. 45, n. 4, p. 923-935, jul. 2014. Disponível em: $<$ http://dx.doi.org/10.1016/j.apergo.2013.11.007>. doi:10.1016/j.apergo.2013.11.007

HIGNETT, S.; McATAMNEY, L. Rapid entire body assessment (REBA). Applied Ergonomics, v. 31, n. 2, p. 201-205, Apr. 2000. Disponível em: <http://dx.doi.org/10.1016/S0003-6870(99)00039-3>. doi:10.1016/S00036870(99)00039-3

IIDA, I.; GUIMARÃES, L. B. M. Ergonomia: projeto e produção. $3^{a}$. ed. São Paulo: Blucher, 2016. $850 \mathrm{p}$. 
IEA, International Ergonomics Association. Definition and Domains of Ergonomics. Disponível em: <http://www.iea.cc/whats/index.html>. Acesso em: 31 mar. 2016.

KLEINER, B. M. Macroergonomics: Analysis and design of work systems. Applied Ergonomics, v. 37, n. 1, p. 81-89, jan. 2006. Disponível em: $<$ http://dx.doi.org/10.1016/j.apergo.2005.07.006>. doi:10.1016/j.apergo.2005.07.006

LIMA, J. S. S.; SOUZA, A. P.; MACHADO, C. C.; OLIVEIRA, R. B. Avaliação de alguns fatores ergonômicos nos tratores feller-buncher e skidder utilizados na colheita de madeira. Revista Árvore, v. 29, n. 2, p. 291-298, 2005. Disponível em: <http://dx.doi.org/10.1590/S0100-67622005000200012>. doi:10.1590/S010067622005000200012

MCATAMNEY, L.; CORLETT, E. N. RULA: a survey method for the investigation of world-related upper limb disorders. Applied Ergonomics, v. 24, n. 2, p. 91-99, 1993. Disponível em: <http://dx.doi.org/10.1016/0003-6870(93)90080-S>. doi:10.1016/0003-6870(93)90080-S

MINETTE, L. J.; SOUZA, A. P.; FIEDLER, N. C.; SILVA, E. N. Carregamento e descarregamento. In: Colheita Florestal. $3^{\mathrm{a}}$ ed. Viçosa: Editora UFV, 2014. p. 162177.

PICOLOTO, D.; SILVEIRA, E. Prevalência de sintomas osteomusculares e fatores associados em trabalhadores de uma indústria metalúrgica de Canoas - RS. Revista Ciência Saúde Coletiva, v.13, n.2, p. 507 - 516, 2008. Disponível em: <http://dx.doi.org/10.1590/S1413-81232008000200026>. doi:10.1590/S141381232008000200026

SILVA, E. P.; MINETTE, L. J.; SANCHES, A. L. P.; SOUZA, A. P.; SILVA, F. L.; MAFRA, S. C. T. Prevalência de sintomas osteomusculares em operadores de máquina de colheita florestal. Revista Árvore, Viçosa-MG, v.38, n.4, p.739-745, 2014. Disponível em: <http://dx.doi.org/10.1590/S0100-67622014000400017>. doi:10.1590/S0100-67622014000400017

SILVA, E. P.; MINETTE, L. J.; SOUZA, A. P.; MARÇAL, M. A.; SANCHES, A. L. P. Fatores organizacionais e psicossociais associados ao risco de LER/DORT em operadores de máquinas de colheita florestal. Revista Árvore, Viçosa-MG, v.37, n.5, p.889-895, 2013. Disponível em: <http://dx.doi.org/10.1590/S010067622013000500011>. doi: 10.1590/S0100-67622013000500011

THUN, J. H.; LERH, C. B.; BIERWIRTH, M. Feel free to feel comfortable - An empirical analysis of ergonomics in the German automotive industry. International Journal of Production Ergonomics, v. 133, n. 2, p. 551-561, out. 2011. Disponível em: <http://dx.doi.org/10.1016/j.ijpe.2010.12.017>. doi:10.1016/j.jpe.2010.12.017

YOON, S. Y.; KO, J.; JUNG, M. C. A model for developing job rotation schedules that eliminate sequential high workloads and minimize between-worker variability in cumulative daily workloads: Application to automotive assembly lines. Applied 
Ergonomics, v. 55, p. 8-15, jul. 2016. Disponível em: <http://dx.doi.org/10.1016/j.apergo.2016.01.011>. doi:10.1016/j.apergo.2016.01.011 